Original Research Article

\title{
Electricity versus hydrogen for passenger cars under stringent climate change control
}

\author{
Hilke Rösler $^{\mathrm{a}, *}$, Bob van der Zwaan ${ }^{\mathrm{a}, \mathrm{b}, \mathrm{c}, *}$, Ilkka Keppo $^{\mathrm{d}}$, Jos Bruggink ${ }^{\mathrm{e}}$ \\ ${ }^{a}$ ECN Policy Studies, Energy research Center of the Netherlands, Petten/Amsterdam, The Netherlands \\ ${ }^{\mathrm{b}}$ Lenfest Center for Sustainable Energy, Earth Institute, Columbia University, New York, USA \\ ' School of Advanced International Studies, Johns Hopkins University, Bologna, Italy \\ ${ }^{\mathrm{d}}$ UCL Energy Institute, University College London, United Kingdom \\ e Institute for Environmental Studies, VU University Amsterdam, The Netherlands
}

\section{A R T I C L E I N F O}

\section{Article history:}

Received 13 May 2013

Revised 10 November 2013

Accepted 22 November 2013

\section{Keywords:}

Transport sector

Oil prices

Climate change

Electricity

Hydrogen

\begin{abstract}
A B S T R A C T
In this article we analyze how passenger car transportation in Europe may change this century under permanent high oil prices and stringent climate control policy. We focus on electricity and hydrogen as principal candidate energy carriers, because these two options are increasingly believed to become the long-term competitors in the transport sector. We complement a concise stylistic analysis with an in-depth investigation performed with the energy system optimization model TIAM-ECN, which we ran only for the European regions for this study. This bottom-up model, belonging to the TIMES family, has been adapted for the purpose of researching - amongst others - the transport sector. We particularly inspect the use of passenger cars and find that, if oil prices amount to $100-150 \$ / \mathrm{bl}$ during the remainder of the century, the transport sector could be little affected in the sense that it may continue to rely predominantly on (liquid or gaseous) fossil fuels: our model suggests that it could be optimal to start replacing gasoline and diesel by natural gas around the middle of the century if sufficient oil and gas reserves are available within this price range. If the European Commission achieves implementing its ambitious carbon mitigation plan, however, a massive restructuring of the transport sector away from fossil fuels could take place, which in three decades would transform it to broadly rely on hydrogen as main energy carrier according to our model runs. Under a broad set of sensitivity scenarios with varying assumptions regarding our most important modeling parameters, we find that if battery costs are reduced by at least $60 \%$ in comparison to our reference cost decline path, the passenger car sector could predominantly run on electricity from around 2050.
\end{abstract}

(c) 2013 Elsevier Ltd. All rights reserved.

\section{Introduction}

Mankind has recently entered an era of persisting high oil prices that will probably not fall much below $100 \$ /$ bl anymore. In parallel there are ongoing efforts from the international community to implement a stringent global climate control policy. The purpose of this article is to investigate how the passenger car sector in Europe may transform under these fundamental changes that will have pervasive repercussions on energy services in all parts of our economy. Our research was initiated by the observation that today, after a wave of seemingly unlimited popularity during the nineties of last century and the first decade of this century for hydrogen fuelled vehicles, hydrogen no longer appears to be the

* Corresponding authors. Address: ECN Policy Studies, Energy Research Center of the Netherlands, P.O. Box 1, 1755 ZG Petten, The Netherlands. Tel.: +31 88515 4429 .

E-mail addresses: rosler@ecn.nl (H. Rösler), vanderzwaan@ecn.nl (B. van der Zwaan). prime candidate energy carrier to fuel the car of the future. Instead, electricity-driven vehicles now are the most publicized option and seem the most promising forthcoming transportation technology. The hydrogen car hype of a decade ago has been replaced by the electric car hype of the late 2000s and early 2010s. This study provides a techno-economic perspective on these two major options, whereby we attempt to contribute to the discussion about which technology will or should ultimately prevail.

Since transportation plays a key role in solving problems of both energy security and climate change (see e.g., [15,29], the search for the dominant future technology in this sector is especially intense. It is not the first time that the promise of the hydrogen car - the deployment of which is seen more generally as one of the key drivers for the establishment of a hydrogen-based economy - has faded by the emergence of the electric car. Electric propulsion for the transport sector was considered several times during the 1970s-1990s after hypes for hydrogen, and today again appears to offer the best hope for change in the nearby future. We argue 
that the recent shift in perception can be traced back to at least four distinct factors: (1) the immediate usability of electric cars given extensive connection opportunities to current electricity networks, (2) the relative immaturity of hydrogen technology in conjunction with large infrastructure requirements and potential safety issues, (3) the economic impact from a fundamental rise of oil prices since 2008 that pushed up the cost of some of the main hydrogen production options more than it increased average electricity prices (especially in countries heavily relying on coal, nuclear or renewables-based power), and (4) the above mentioned "hype cycle", which has punished hydrogen technology for being unable to meet earlier high expectations as fast as it was hoped for (see, for example, [4].

The battle for the car of the future is shaped by ambitious intentions from industry, preferences from the public, societal hypes as well as uncertain economic conditions and environmental factors. Technical issues such as the driving range and recharging speeds for electric cars need to be improved, while for hydrogen cars the roll-out of a widespread fuel station network is an absolute necessity. Ultimately, however, the prospects for different car concepts are first and foremost a function of comparative techno-economic performance. Crucial factors for both electric and hydrogen vehicles are the cost developments of their key components, in particular the battery and fuel cell respectively. Upfront investment costs for both technologies need to decline, while simultaneously their lifetime needs to increase to reach substantial decreases in overall vehicle lifetime costs. The other most important economic factors are the development of world oil prices and the evolution of fiscal regimes for vehicles and fuels including carbon taxes. Non-economic aspects like personal tastes and the willingness of people to change their habits will significantly influence the introduction of new car technologies. These important facets are, however, not taken into account in our techno-economic analysis and we refer the reader to other studies, such as Lebutsch and Weeda [25], McKinsey [28], Schäfer et al. [35] and Yeh et al. [45], for complementary analyses on aspects such as infrastructural hurdles, political obstacles and social acceptance. Techno-economic analysis on passenger car choices in relation to emissions reduction impacts has been undertaken also by others, but, some of these studies focus on other low carbon options such as biofuels $([6,38,9])$ or do not include hydrogen or electric vehicles $([43,44,39])$, while yet other studies lack aspects of competition ([7,24,30]). Most similar to our work are studies by Anandarajah et al. [2], Grahn et al. [10] and Akashi and Hanaoka [1], but these have a global scope or more limited time horizon until 2050.

In the Stylic assessment below, we adopt a consumer perspective for which we carry out a stylistic assessment of the levelized costs per kilometer of four major car types. In Energy systems analysis: TIAM, we describe our bottom-up energy technologies approach in which decisions are taken in a setting of a social planner who optimizes the overall costs of the European energy system that includes a range of different vehicle types. In Energy system results, we report our main results and examine the robustness of our outcomes through multiple sensitivity tests with regard to our key assumptions. We conclude in Discussion and conclusion.

\section{Stylistic assessment}

We first develop a stylized evaluation of the competition between different future car technologies (see also [5]). This assessment captures quantitatively the essence of the competitive forces involved, and proffers a broad perspective of potential outcomes based on key assumptions regarding the combined effects of technological progress (reflected in vehicle costs), fuel price developments (of crude oil, electricity and hydrogen) and fiscal regimes (like tax rates on vehicles and fuels including carbon prices). As main indicator for their relative economic fitness, both at present and in the future, we use the levelized costs per kilometer for owners of different vehicle concepts. From a consumer perspective several relatively straightforward observations can thus be made with regards to the diffusion potential of electric vis-àvis hydrogen-based cars.

In our stylized context we consider four different types of passenger cars: internal combustion engine vehicles (ICEs) that use conventional fuels such as gasoline or diesel (that in practice may either be or not be mixed with biofuels); ICEs that are fuelled with natural gas; battery-based electric vehicles (BEVs); and fuel cell vehicles (FCVs) running on hydrogen. We include in this assessment natural gas as separate option to fuel cars, as no intrinsic economic reasons exist that would inhibit their widespread adoption. Possible additions of disperse unconventional resources to the current centralized reserve base may further strengthen the broad diffusion feasibility of natural gas as fuel for car transportation. The fact that to date natural gas cars are relatively uncommon in most of the world is probably induced by factors related to, for instance, distribution infrastructures, industrial choices and consumer preferences, which are mostly outside our capacity to investigate. To keep our analysis simple we assume henceforth that biofuels are not mixed with conventional fuels. We also exclude ICEs fuelled by only biofuels as a separate option in this assessment, because biofuels are in most cases mixed with traditional transportation fuels. Also hybrid versions between our four main vehicle options are not considered in our stylized inspection, as they do not proffer any additional insights. Multiple biofuel and hybrid options, however, are included in our more detailed energy systems analysis in the next section.

For comparing these main car categories we assume that all four types are used to drive $12000 \mathrm{~km}$ annually. In Rösler et al. [33] and van der Zwaan et al. [41] we report our assumptions regarding vehicle performance and fuel efficiency improvements. In order to compute the levelized costs per kilometer for our four basic car types, assumptions need to be made regarding vehicle investment requirements and fuel (distribution) prices plus taxes. For the year 2020 our assumptions for the purchase costs of these car concepts, as well as for fuel prices, distribution costs and taxation levels are given in Table 1 . The investment costs reported in Table 1 are mainly based on data available from IEA [18]. We assume that IEA's near-term estimates correspond to 2020.

For the following decades investment costs are assumed to reduce to the values described in Energy systems analysis: TIAM (Fig. 3). They decrease most markedly for BEVs and FCVs. The untaxed fuel price at the refinery is assumed to be $0.61 \$ /$ liter - based on constant oil prices of $100 \$ / \mathrm{bl}$, a refinery efficiency of $85 \%$, and a refinery cost margin of $0.06 \$ /$ liter - and we suppose a fuel distribution margin of $0.16 \$ /$ liter (see e.g. [5]). We suppose that gas prices in Europe remain constant at $0.36 \$ / \mathrm{m}^{3}$, and that additional costs for transportation and distribution of gas amount to 0.22 $\$ / \mathrm{m}^{3}$. Based on a representative composition of European electricity generation in 2020 (25\% coal, 24\% gas, 22\% nuclear and 29\% renewables including hydropower; see [19], the electricity price is assumed to be $0.08 \$ / \mathrm{kWh}$ in 2020 and afterwards. We use a distribution cost margin of $0.04 \$ / \mathrm{kWh}$, as was assumed by Bruggink and Rösler [5], but recognize that this figure could in reality be significantly higher e.g., due to additional recharger costs. Hydrogen is estimated to cost approximately 29 \$/GJ in 2020 and $27 \$ / G J$ in 2040, under the assumption that all hydrogen is produced through steam methane reforming (SMR) plants with an efficiency of $75 \%$ and a cost margin of $1.9 \$ / G J$ in 2020 and $1.7 \$ /$ $\mathrm{GJ}$ in 2040. Additional transport and distribution costs for hydrogen are assumed to be $18 \$ / G J([5])$. Fuel taxation is supposed to stay as in the current fiscal regime of a typical (average) European 
Table 1

Main cost assumptions* for our four basic car types in 2020 for our stylistic analysis.

\begin{tabular}{|c|c|c|c|c|}
\hline & Car investment cost & Fuel price & Fuel distribution cost & Fuel taxation \\
\hline ICE current fuels & $\$ 22800$ & $0.61 \$ /$ liter & $0.16 \$ /$ liter & $0.72 \$ /$ liter \\
\hline ICE natural gas & $\$ 24300$ & $0.36 \$ / \mathrm{m}^{3}$ & $0.22 \$ / \mathrm{m}^{3}$ & $0.10 \$ / \mathrm{m}^{3}$ \\
\hline BEV electricity & $\$ 39600$ & $0.08 \$ / \mathrm{kWh}$ & $0.04 \$ / \mathrm{kWh}$ & $0.12 \$ / \mathrm{kWh}$ \\
\hline FCV hydrogen & $\$ 37100$ & $29 \$ / G J$ & $18 \$ / G J$ & $3 \$ / G J$ \\
\hline
\end{tabular}

* All cost data are quoted in US dollars of 2005

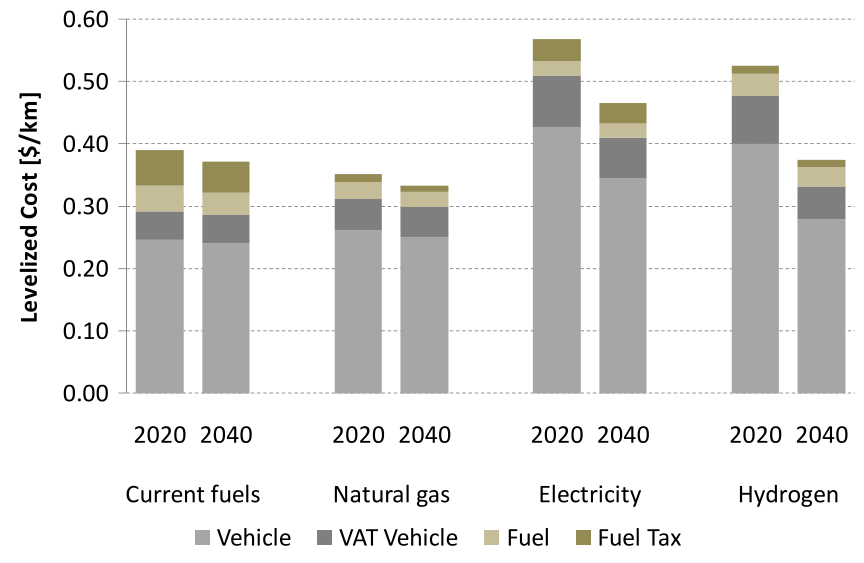

Fig. 1. Levelized cost per kilometer for four types of passenger cars under a typical current European fiscal regime when oil prices are $100 \$ / \mathrm{bl}$.

country. This implies excise duties on gasoline of $0.72 \$ /$ liter, on natural gas of $0.10 \$ / \mathrm{m}^{3}$ and on electricity of $0.12 \$ / \mathrm{kWh}$. No European hydrogen tax exists to date, but we assume it will one day be introduced if there is prospect of it being used on a large scale (perhaps already in 2020) and may then amount to the same as currently levied on natural gas. This translates into an excise duty of $3 \$ / G J$.

With these assumptions we calculate the total levelized costs per kilometer for each of the four main vehicle types, the results of which are depicted in Fig. 1. Cars are assumed to have an economic lifetime of 10 years and contributions to levelized costs, quoted in (2005) US\$/km, are discounted with a rate of $5 \% / \mathrm{yr}$. Overall levelized costs are disaggregated in four segments: vehicle investment costs (excluding VAT), the costs associated with VAT (corresponding to $19 \%$ of investments in our example, as in many European countries), untaxed fuel costs, and excise duties on fuels (including VAT). As can be seen in Fig. 1, for all four cases the purchasing of a vehicle constitutes the major part of total levelized costs. Levelized investment costs are relatively low for ICE vehicles that run on conventional fuels or natural gas, in comparison to BEVs and FCVs. Especially the latter two car types, however, have substantial potential for manufacturing cost decreases. Total levelized costs are lowest for ICEs running on natural gas, mostly due to lower fuel tax costs. This is the result of the assumed fiscal regime that works out more in favour of gas than fuels like gasoline or diesel. Also FCVs benefit from this tax system, which, together with our assumption concerning vehicle cost reductions, brings their levelized cost in 2040 to the level of ICEs running on conventional fuels. Despite the fact that BEVs incur the lowest fuel costs, high excise duties on electricity and especially high investment costs render BEVs the most expensive alternative among these competing vehicle concepts today and in the foreseeable future.

It is improbable that fiscal regimes will remain stable over the next several decades. If in the future excise duties for natural gas and hydrogen are brought more in conformity with those currently levied on gasoline - not an unlikely scenario if these become

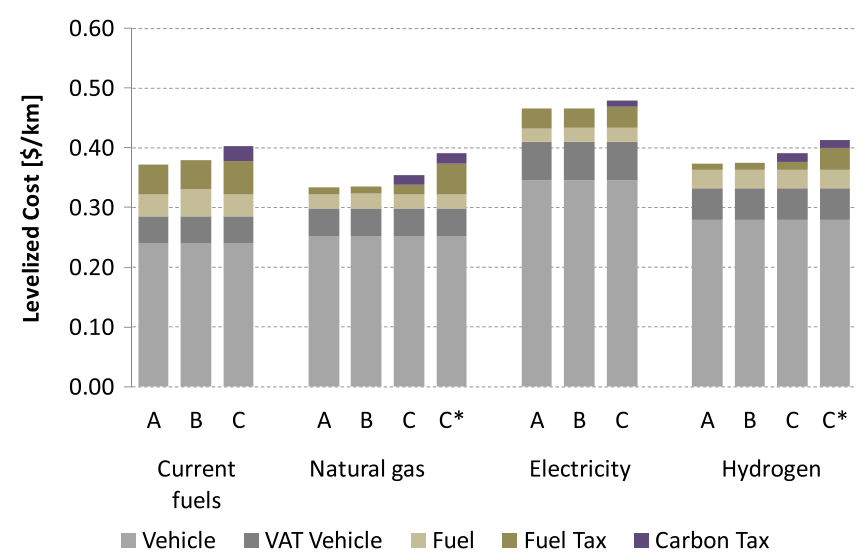

Fig. 2. Levelized cost per kilometre in 2040 for four types of passenger cars in four scenarios with varying assumptions on oil prices and carbon taxation: (A) reference scenario, (B) high oil price scenario, (C) high $\mathrm{CO}_{2}$ price scenario, and $\left(\mathrm{C}^{*}\right)$ high $\mathrm{CO}_{2}$ price scenario with higher fuel taxation of natural gas and hydrogen.

wide-spread fuels for the transport sector - the competitve ranking order depicted in Fig. 1 could alter. Similarly, we assumed for the computations reported in Fig. 1 that energy prices will stay at today's level, which is unlikely. It is plausible that the limited availability of liquid and gaseous fossil energy reserves, as well as the implementation of climate control policies, will lead to increases in fossil energy prices and some sort of carbon pricing, in which case the mutual competitivity of our four car types can change. The influence of increased energy prices and the introduction of global climate policy on levelized vehicle costs is shown in Fig. 2 for the year 2040. As can be seen, an additional cost category is included for carbon taxation. The reference scenario $(A)$ is the same as presented in Fig. 1, involving an oil price of $100 \$ / \mathrm{bl}$ and the current fiscal regime. In the high oil price scenario (B), the oil price is assumed to be $150 \$ / \mathrm{bl}$ (a level that was briefly reached in the recent past, and that is close to a factor 2 higher than the average over the last 5 years). We assume that gas prices are not fully decoupled from oil prices but partly follow them: if oil prices increase from 100 to $150 \$ / \mathrm{bl}$, gas prices increase from 0.36 to $0.46 \$ / \mathrm{m}^{3}$ (which impacts electricity and hydrogen production costs).

In the high $\mathrm{CO}_{2}$ price scenario $(\mathrm{C})$, a carbon tax of $200 \$ / \mathrm{tCO}_{2}$ is levied. This carbon tax - an order of magnitude higher than values experienced so far in the European Emissions Trading System, and consistent with what integrated assessment models predict for the middle of the century under a relatively stringent global climate control regime - will probably lead to a broad diffusion of low-carbon options, including biofuels, renewable energy and CCS in the electricity and hydrogen production mix. For ease of exposition, however, we still assume that biofuels are not mixed with conventional fuels, and that electricity and hydrogen have the same production-portfolio-based upstream $\mathrm{CO}_{2}$ emissions as in scenarios $A$ and $B$. The oil price in scenario $C$ is $100 \$ / b l$, like in scenario $A$. In a supplementary scenario $\left(C^{*}\right)$ we increase the excise duty on natural gas and hydrogen to a level comparable, in terms of energy content, 
to that levied on gasoline, that is, $23 \$ / \mathrm{G}$ for hydrogen and $0.80 \$ / \mathrm{m}^{3}$ for natural gas. Fig. 2 shows that high oil prices affect most the levelized costs of ICEs using current fuels. Consequently, they become slightly more expensive than FCVs using hydrogen (although in the light of the wide range of uncertainties connected to any single estimate of future cost elements the difference is quite negligible, so that few decisive conclusions can be made based on such a difference only). The high oil prices of scenario B only moderately influence the costs of vehicle types other than ICEs. As in scenario A, natural gas based ICE vehicles remain the cheapest means of transportation. A similar observation can be made for scenario $C$ and $C^{*}$. The carbon tax particularly increases the levelized costs of ICEs using current fuels. Natural gas based ICEs remain the least cost option, followed by hydrogen based FCVs. If, however, excise duties for natural gas and hydrogen are increased (as in scenario $C^{*}$ ), our results show that the levelized cost of FCVs becomes slightly higher than those for ICE using current fuels. The cost of driving a natural gas fuelled ICE increases too, closer to the cost of ICEs running on current fuels and FCVs. Hence overall we can conclude that although purchase investments constitute the largest contribution to total levelized costs for all car types, other cost components such as related to fuel prices and tax measures (including excise duties and carbon taxes) can be decisive in the ultimate competition between different vehicle types.

The results plotted in the histogram of Fig. 2 could in principle look quite different if we had chosen another discount rate. A higher value than the one we picked, for instance, may reflect the fact that people tend to disproportionally focus on upfront investment costs in comparison to the potential for future fuel savings (which is the reason why 'discount rate' in this context can also be referred to as 'hurdle rate'). Implementing a higher discount rate would disfavour options with higher investment requirements like BEVs and FCVs, but not so much that the relative competitivity of our four options becomes entirely indifferent under changes in fuel and tax charges. Increasing energy prices and climate control measures enhance the importance of fuel prices and carbon taxes as parts of the levelized costs per kilometer to such an extent that our main conclusion continues to hold: cost components other than investments may be decisive in terms of which car becomes most competitive. This finding is especially displayed in the likely case that, under high energy prices and the threat of climate change, consumers switch to alternative fuels such as biofuels, biogas and low- or zero-carbon electricity and hydrogen, which may (or not) have higher fuel costs but lower or no carbon tax.

Although undoubtedly the transportation sector will change under increasing energy prices and/or stringent climate control measures, the precise nature of this transformation remains uncertain. Our stylistic analysis may give some insight into what appears most rational from a consumer's point of view under assumptions that seem plausible at the moment. One of the fundamental reasons for the prevailing uncertainty regarding forecasts of what transportation will look like in the future is that the transport sector is intimately linked to, and dependent on, energy systems, technologies and resources in other economic sectors. For example, the possibly limited regional availability of cheap renewable forms of energy which will undoubtedly play a key role in decarbonising the global energy system - can lead to competition for these technologies between different sectors, and should ultimately lead to their utilization in those sectors where they are deemed most cost efficient. To take such aspects better into account than in our stylistic assessment, when attempting to analyse the question which option could become the dominant technology for the car of the future in a carbon-constrained world with increasing energy prices, it is instructive to use an integrated energy systems model such as TIAM.

\section{Energy systems analysis: TIAM}

TIAM is a member of the family of technology-rich bottom-up energy systems models based on the TIMES platform and is described in detail by its original developers in Loulou and Labriet [26] and Loulou [27]. TIAM (TIMES Integrated Assessment Model) is a linear optimization model simulating the development of our global energy economy from resource extraction to final energy use over a period of over 100 years. Its regional disaggregation separates the world in to a number of distinct geographical areas (15, for the version used at ECN) including East and West Europe. The objective function of TIAM consists of the total discounted aggregated energy systems costs calculated over the full time horizon and summed across all regions. Running scenarios with TIAM involves minimizing this objective function. The main cost components included in the objective function are the investment costs and fixed plus variable operation and maintenance costs. Smaller cost components such as decommissioning costs are also included. Since TIAM is based on a partial equilibrium approach with demands for energy services responding to changes in their respective prices through end-use price elasticities, savings of energy demand and corresponding cost variations are accounted for in the objective function as well. Although fuel taxes may make up a considerable part of the overall levelized costs incurred in the transport sector (as shown in our stylistic assessment), and might thus substantially influence the car choice for individual consumers, we do not model excise duties on fuels in TIAM. The reason is that they are not seen as net costs from an overall energy system perspective as they are revenues for the implicit central planner. The database associated with TIAM includes hundreds of technologies for a broad set of different sectors. The prices of fuels including their carbon footprint are determined endogenously by the model (as shadow prices, such as resulting from $\mathrm{CO}_{2}$ emission targets) and are therefore not an input but a result of model runs. For a general description of the reference energy system of TIAM see also Syri et al. [37].

\section{TIAM-ECN: transport sector}

TIAM-ECN is a leaner version of the original TIAM integrated assessment model, operated at ECN with recent development emphasizing the modeling of the European energy sector. TIAMECN has been extensively described in Rösler et al. [33]. In short, this altered version keeps all the main characteristics as well as many of the details of the original TIAM, but includes a series of modifications, elaborations and improvements, notably with regards to the transport sector. Many of the changes relate to updated input data for essential technical and economic parameters, as well as the introduction of growth and decline constraints for various resource and end-use applications. They also involve several simplifications, such as more aggregated sectoral and technological detail for those parts of the model that we considered to be overly complex in perspective of TIAM's global orientation and, moreover, the specific purposes of this study.

In Rösler et al. [33] we extensively describe our main car technology assumptions for the 13 types modeled in TIAM-ECN, particularly in terms of vehicle costs and efficiencies today as well as how they develop in the future. Of the 13 simulated car technologies, 5 are assumed not to decrease further in costs: standard and advanced diesel cars, standard and advanced gasoline cars and liquid petroleum gas (LPG) cars. We assume that the average fuel consumption per distance travelled for these relatively common car types continues to decrease during future decades. The remaining 8 car types are assumed to be subject to simultaneous cost and efficiency improvements: cars running on natural gas, hybrid electric cars using diesel, gasoline or natural gas, 2 types of plug-in hy- 
brids (diesel and gasoline based), electric cars and fuel cell cars running on hydrogen.

\section{TIAM-ECN: recent updates}

For the exercises reported in this article we have introduced several important modeling changes with respect to our last two papers $[23,41]$. First, we have significantly modified the hydrogen sector. We updated the techno-economic data for all hydrogen production technologies to better represent the current state-of-theart, and included decentralized electrolysis. We refined the representation of hydrogen distribution by enlarging the number of hydrogen transportation options and distinguishing particularly between hydrogen transportation through trucks and pipelines, as described in Rösler et al. [33]. In addition, we improved the modeling of the build-up of hydrogen transmission infrastructures to better take into account the real-life diversity in delivery options, the cost-optimality of which is largely determined by the volume of total hydrogen demand along with the required delivery distance. Since it is difficult to accurately take into account the geographical distribution of energy demand in a model with limited spatial information like TIAM-ECN, we took as rough approximation that in the first stages of development hydrogen is likely to be transported predominantly by truck, and that in later phases an elaborate hydrogen pipeline system is required (with a small share of hydrogen still being transported by truck).

Second, we have improved the description of biofuels used in transportation. The European potentials for solid biomass from waste and bio-energy crops were updated using data from the RES2020 project [31]. We have also included a simplistic representation of land-use availability and competition between different energy crops. In the updated version of our model it is possible to trade biomass and biofuels between East and West Europe, which allows for an expansion of their use. Due to sustainability concerns regarding the trade of bioenergy from outside Europe, we do not include this option in our model. A large series of techno-economic data for biofuels production technologies were updated to reflect several recent developments, and several new production technologies were implemented such as ethanol and synthetic natural gas (SNG) production from solid biomass. Third, we have updated several demand projections, including for simulated transportation distances, by using GDP projections from the recent Energy Technologies Perspectives report as drivers for the development of multiple energy services [20]. Fourth, our new model version covers electricity production from fossil fuels cofired with biomass and complemented with CCS, which in principle yields an option to realize negative $\mathrm{CO}_{2}$ emissions. Also CCS as mitigation option in industry was remodelled.

These clusters of modifications allow us to achieve significantly deeper cuts in $\mathrm{CO}_{2}$ emissions than we were able to retrieve in our previous work. Another difference with respect to the model version used in earlier papers is that for the research presented here we employ TIAM-ECN to investigate Europe only. By reducing TIAM-ECN to only two (European) regions instead of the usual 15 , trade flows are no longer an endogenous model result. Consequently, the original trade options between different regions is replaced by import and export streams between the two European regions only, while a single 'rest of the world' represents the sum of the omitted trade regions. Trade between East and West Europe remains modelled endogenously, but prices for gas, oil and coal products imported from outside Europe are now determined by exogenously defined supply cost curves.

\section{TIAM-ECN: scenarios and key assumptions}

For the purpose of this article we investigated a series of different scenarios and variations thereof. For one group of scenarios we varied the oil prices: starting from prices in $2005(50 \$ / b l)$ and $2010(100 \$ / \mathrm{bl})$ we let the long term oil price range from 50 up to $200 \$ / \mathrm{bl}$ in the alternative scenarios. When these values are reached depends on the scenario: in the $150 \$ /$ bl scenario the maximum is reached by 2030 , in the $200 \$ /$ bl case by 2050 (the oil price is assumed to remain constant throughout the remainder of the century). We focused in particular on the levels $100 \$ / \mathrm{bl}$ and $150 \$ / \mathrm{bl}$ : the former because this is essentially the value observed today, the latter while such as price may well prevail over the decades to come. In another group of scenarios we implemented different climate control strategies. For our analysis of the European transport sector we designed one that corresponds as closely as possible to the current climate change mitigation target of the European Commission, hereafter referred to as 'stringent climate control scenario' or 'ambitious $\mathrm{CO}_{2}$ emissions reduction path'. In this scenario we assumed a reduction of $\mathrm{CO}_{2}$ emissions in 2020 of $20 \%$ with respect to their level in 1990 , with a linear decrease down to $80 \%$ in 2050 , after which emissions stay constant for the remainder of the century. It is largely believed that, if other regions in the world follow suit with similar measures, this emission abatement path has a non-negligible probability to remain compatible with the goal of limiting the global average surface temperature increase to $2{ }^{\circ} \mathrm{C}$. The TIAM-ECN model includes a large number of possibilities to reduce emissions in the energy sector; see van der Zwaan et al. [41] for a description of the main clusters of mitigation options.

Since the investment costs of a car constitute the major part of the levelized vehicle costs per kilometer - so that assumptions with regard to these capital costs strongly affect the outcome of any analysis in this field, whether stylistic or through detailed energy systems scenario modelling - we specify them here in more detail. Because the purchase costs of BEVs and FCVs are currently much higher than those of ICE cars consuming conventional fossil fuels, findings with TIAM-ECN crucially hinge on the extent to which we suppose future cost reductions for particularly BEVs and FCVs. The main cost components of BEVs and FCVs are the battery and fuel cell, respectively, which account for at least half of total vehicle costs. This is a significantly higher share than a conventional engine contributes to the overall costs of ICE vehicles. Both battery and fuel cell technologies, however, have allegedly good cost decline prospects, which we simulate in TIAM-ECN.

Table 2 lists the near-term cost reduction steps we adopt for battery and fuel cell systems. For batteries these projections are based on the near- and long-term forecasts by the IEA [18], which are consistent with Gül [12] and fall in the cost range reported by McKinsey [28] and Anderson and Patiño-Echeverri [3]. For fuel cells we used several sources, including IEA [16,17], Gül [12], McKinsey [28] and Schoots et al. [36]. As can be seen from Table 1, we expect fuel cell costs to go down more significantly than battery costs. Learning curve studies justify our more optimistic assumptions for fuel cells: Schoots et al. [36] and Rivera-Tinoco et al. [32] find that for a large range of different fuel cell types the learning rate (that is, the relative cost reduction with every doubling of manufactured capacity) is typically around $20 \%$. In some cases it is even significantly higher, for example if phenomena such as economies-of-scale and automation are accounted for. To our knowledge no such learning rates have been reported in the peer-reviewed scientific literature for battery technology, possibly since it is already relatively mature, which is why sometimes a rather ad hoc value for the learning rate for batteries of $10 \%$ is assumed [21]. Also, given the current widespread use and multiple applications of batteries, there is less deployment 'doubling potential' left for batteries in comparison to fuel cells, so that significant cost reductions for batteries seem realizable only over a period of decades, unless new advanced kind of batteries are developed that are significantly improved over current types. 
Table 2

Reference assumptions in TIAM-ECN for battery and fuel cell cost developments.

\begin{tabular}{|c|c|c|c|c|}
\hline Costs & Related assumptions on (storage) capacity & 2020 & 2030 & 2040 \\
\hline Battery $[\$(2005) / \mathrm{kWh}]$ & $44 \mathrm{kWh}$ (near term) and $36 \mathrm{kWh}$ (long term) for $200 \mathrm{~km}$ driving range & 450 & 390 & 330 \\
\hline Fuel cell $[\$(2005) / \mathrm{kW}]$ & $80 \mathrm{~kW}$ system & 180 & 80 & 50 \\
\hline
\end{tabular}

N.B., note the different units used for batteries respectively fuel cells.

For batteries we use data from IEA [18], while fuel cell data are based on IEA [16,17], Gül [12], McKinsey [28] and Schoots et al. [36].

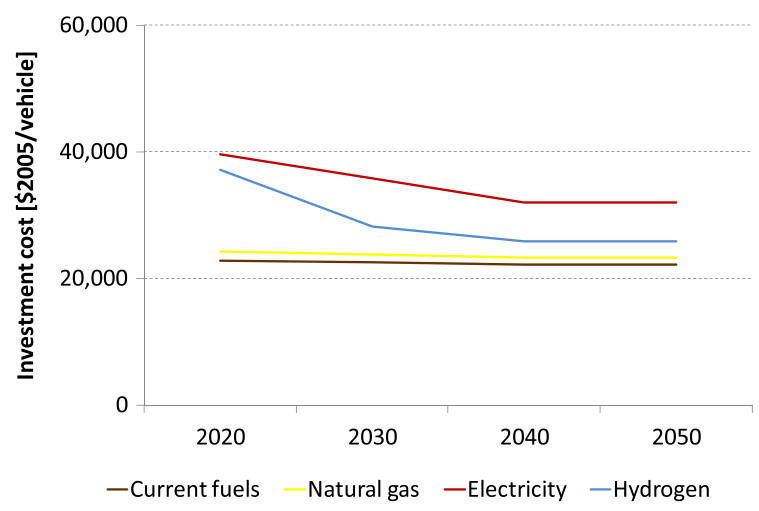

Fig. 3. Development of investment costs in TIAM-ECN for four main types of passenger cars.

Today the lifetime of batteries and fuel cells is shorter than that of the car in which they are installed. Hence they normally would need to be replaced during the vehicle's life. This increases the car's overall costs substantially. Like other analysts suppose in similar studies, we assume that when the moment of mass production of BEVs and FCVs has arrived, battery and fuel cell technology will have progressed such that their lifetime matches that of a car, so that issues of limited duration of essential components do not incur additional costs. Fig. 3 depicts how the assumptions listed in Table 1, together with the rest of the car costs, translate in capital cost requirements per vehicle until the middle of the century for each of our four main car types. For a description of all other techno-economic parameter assumptions, such as regarding fuel efficiency, related to the passenger transport sector, especially BEVs and FCVs, see Rösler et al. [33].

\section{Energy system results}

Central scenario runs
In a first set of scenario runs we inspect the impact of varying oil price assumptions on the nature of the transport sector modelled by TIAM-ECN. Fig. 4 shows the development of energy use by passenger cars in Europe per energy carrier for two different oil price scenarios. In Fig. 4(a) it is assumed that oil prices retain a level of $100 \$ / b l$ throughout the century. As illustrated, the currently dominant fuels gasoline and diesel continue to be essentially the only energy carriers used for fuelling passenger cars for another few decades, and for about the coming half a century at least they will remain the main options to fuel cars in Europe. Total energy consumption by passenger vehicles continues to increase, especially (but not only) as a result of considerable growth potential for car usage in East Europe. Consequently, energy consumption in the transport sector in 2100 is about 2 times higher than in 2010 . When oil prices are consistently $150 \$ /$ bl from 2030 onwards, as assumed in Fig. 4(b), the total energy use by cars is somewhat reduced due to the use of more efficient cars as reaction to increased prices during the first half of the century, but remains more or less unaffected during the second half, so that the level in 2100 is about the same as in the $100 \$ /$ bl scenario. Overall, the differences between these two scenarios are limited.

For both oil price cases, one may question whether globally available oil reserves are sufficient to allow these results. It proves that the importance of liquid fossil fuels used for transportation 'crowds out' their use in other sectors such as industry, which enhances their longevity as dominant option for the transport sector. In both scenarios natural gas rapidly replaces current traditional fuels from around 2050 onwards, such that by the end of the century it obtains a $100 \%$ share in total energy use. This appears realistic from a cost perspective, given that gas cars are, from a technoeconomic point of view, close to competitive already today. Once conventional fuels have been depleted, infrastructure and/or other obstacles that currently inhibit the diffusion of gas cars may more easily be overcome. Whether industrial and consumer preferences allow for such a broad usage of gas in the transport sector is a question our methodology cannot answer. It is uncertain also whether global natural gas reserves are large enough to support its massive use in Europe for several decades. Unconventional resources such as shale gas and methane hydrates may need to complement conventional reserves, but the political feasibility of their large-scale (a)

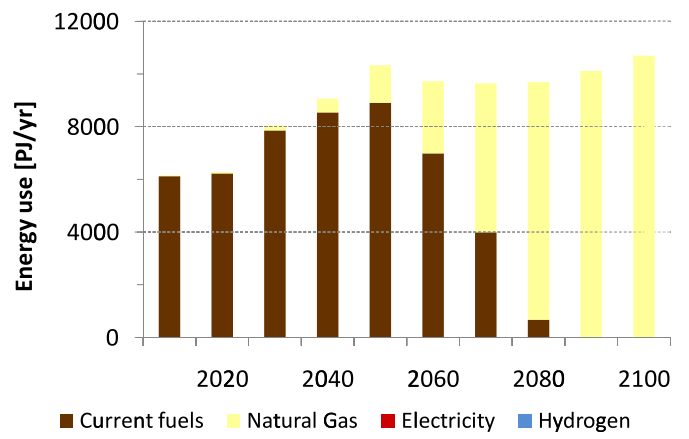

(b)

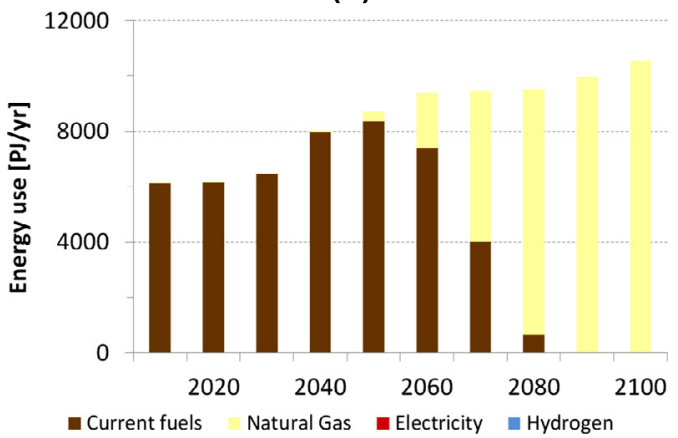

Fig. 4. Energy use by fuel type (in PJ/yr) for passenger cars in Europe when oil prices are (a) $100 \$ / b l$ and (b) $150 \$ / b l$. 
exploitation as well as their environmental impact and overall affordability are uncertain even in countries already producing unconventional natural gas. In our sensitivity analysis we show the effect of reducing our natural gas reserve assumptions by an order of magnitude.

In our second set of scenarios the effect of the imposition of a stringent climate constraint is investigated. For the central stringent climate control scenario, including an oil price of $100 \$ /$ bl plus a stringent $\mathrm{CO}_{2}$ emissions reduction path, the two plots in Fig. 5 depict the energy use per transport fuel type and the corresponding distance travelled in vehicle kilometers respectively. Fig. 5(a) shows a steep decline of overall energy use for passenger cars in Europe after 2030. This is the result of performance improvements of ICE vehicles and especially the broad diffusion of FCVs, which possess a higher efficiency than ICEs (while downstream at the car level such efficiency gains are obvious, they may be less evident from a well-to-wheel perspective, which we do not examine here). After 2050 energy use increases again in order to match the increasing number of cars driven in especially East Europe. As can be seen in Fig. 5(a) and (b), ICEs combusting current fuels remain the dominant type of transportation for another couple of decades, but after 2030 rapidly lose importance and cease to play a role altogether after 2050 as a result of mandatory $\mathrm{CO}_{2}$ emissions abatement. Cars running on natural gas penetrate around 2020, after which they continue to play a non-negligible role until the end of the century. The reason is that these cars are cost-efficient and possess sufficiently low carbon footprint to allow a certain market share. In several countries the infrastructures are or could be rendered available that could support such a role for gas fuelled cars.

As a result of the climate constraint, FCVs first introduced around 2020 start dominating passenger transportation from 2050 onwards and account for most of the private vehicle sector for the remainder of the century. The large expansions of FCVs observed during several decades (e.g., from 2040 to 2050) may appear unrealistically high, e.g. from an infrastructural point of view, but may not be unfeasible if one realizes that the required $20 \% / y r$ growth rate has been observed in several energy sub-sectors (for instance for solar technology). From a comparison between Figs. 4(b) and 5(a) we see that our high oil price assumption has clearly much less impact on energy use in the transport sector than our stringent climate control scenario: most markedly, a deep cut in emissions implies the use of a fundamentally different energy carrier (climate neutrally produced hydrogen) while high oil prices merely produce a shift from current fossil fuel types (gasoline and diesel) to another one (natural gas) that is closely competitive with oil usage and for which reserves are in theory available once those for oil have been depleted. The large difference between these two scenarios is not surprising, since carbon prices (calculated endogenously by TIAM-ECN on the basis of the emissions cap) increase exponentially this century, from values of around $50 \$ / \mathrm{tCO}_{2}$ in 2020 to close to $1000 \$ / \mathrm{tCO}_{2}$ in 2100 . This translates into an effective oil price increase to around $500 \$ / \mathrm{bl}$, calculated from the carbon content of the fuel and the implied emission tax. This is considerably higher than the $150 \$ / \mathrm{bl}$ assumed in our high oil price scenario.

From Fig. 5 we see that a transformation of the transport sector only really kicks in from around 2030 - the reason being that other energy-intensive economic activities, such as the power sector, react to emissions control earlier, as we also concluded in our previous study [41]. The energy carriers employed in the transport sector are now modified several decades earlier than in our prior analysis. This is primarily the result of the greater stringency of our climate control scenario. The hydrogen needed to fuel FCVs needs to be low in carbon-intensity, since FCVs penetrate only following our climate change constraint. As with electricity generation, multiple ways exist to produce low-carbon hydrogen. Fig. 6 shows our results for the hydrogen production mix. As it proves, the growth in volume of hydrogen originates mostly from natural gas (SMR), for which the resulting $\mathrm{CO}_{2}$ is captured and stored underground. As can be seen, small quantities of hydrogen are produced by coal gasification and biomass combustion technologies, both also equipped with CCS. In this scenario the full $\mathrm{CO}_{2}$ storage potential of Europe, which is around 87 Gton $\mathrm{CO}_{2}$ ([14], is exhausted and of which around $20 \%$ is used for $\mathrm{CO}_{2}$ captured in hydrogen production processes. A small part of the hydrogen produced is mixed into the natural gas network, but only at the per-

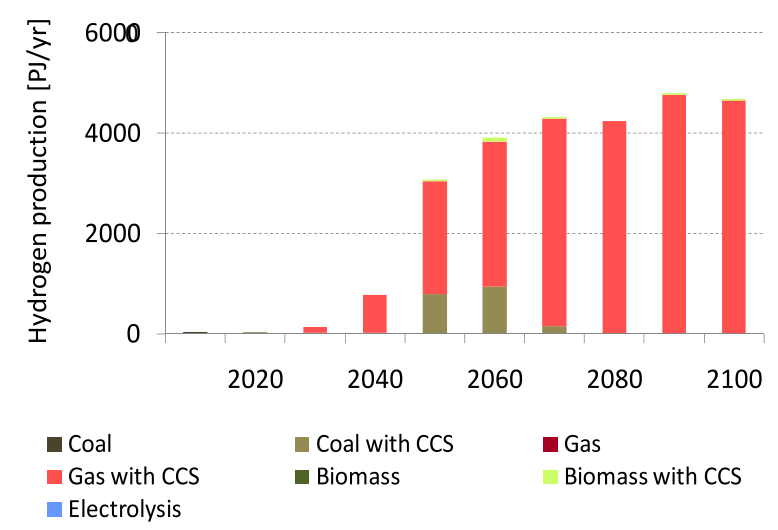

Fig. 6. Hydrogen production mix (in $\mathrm{PJ} / \mathrm{yr}$ ) in Europe under stringent climate policy and $100 \$ / \mathrm{bl}$ oil prices. (a)

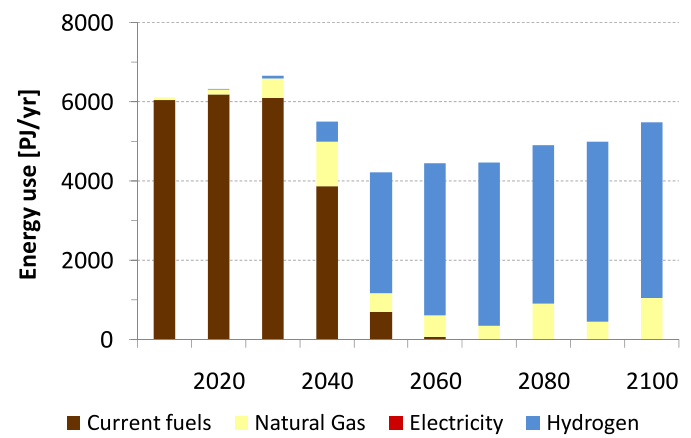

(b)

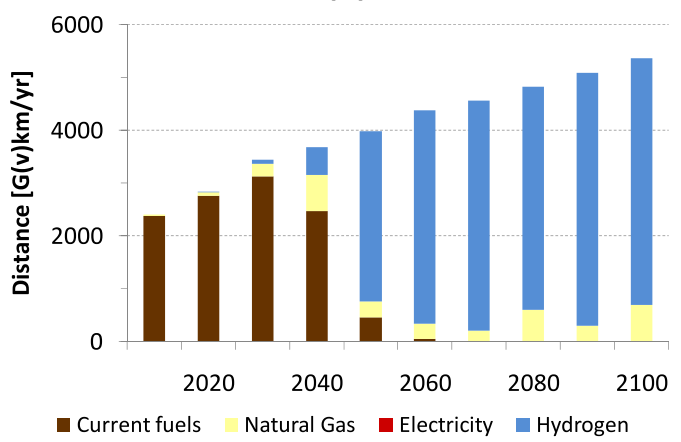

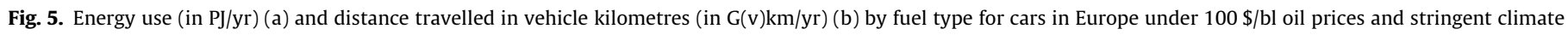
policy. 
centage level compared to the amount used in cars.

A striking finding is that Fig. 5 is dominated by hydrogen during the second half of the century, rather than electricity. This onesided outcome can be explained by the high upfront costs of electric cars (in comparison to those of FCVs) and in particular by those of the batteries (in comparison to fuel cells) with which they operate. In the next section we show how our results would change in case it turns out that battery costs will decline more than we have assumed in our central scenario runs, or if our assumed prospects for fuel cells turn out to be overly optimistic.

\section{Sensitivity analysis for battery and fuel cell costs}

As a first robustness check of our results we perform a sensitivity analysis with regard to our battery costs assumptions. Fig. 7 shows the total distance travelled per type of energy carrier in 2050 for eight different battery cost scenarios under our stringent climate target and with oil prices of $100 \$ / \mathrm{bl}$ throughout the century. Our assumptions regarding fuel cell costs are not altered. The first bar shows the central stringent climate control scenario with reference battery costs declining as described in the Table 2. Subsequent bars represent cases in which the costs of batteries reduce more rapidly. For example, the second bar depicts the outcome of our model under the assumption that battery costs reduce linearly to $10 \%$ lower values in 2040 and maintain that $10 \%$ cost margin with respect to the reference costs assumptions for the rest of the century. From Fig. 7 we observe that implementing a battery cost reduction assumption up to $40 \%$ leaves our results essentially unchanged: the vast majority of passenger car kilometers driven remain through FCVs. Only if batteries follow a $50 \%$ additional cost reduction path (thus if they will be only half as pricy from 2040 onwards with respect to what we assume for the reference projections), then BEVs obtain a significant market share of almost $50 \%$ in 2050 . Under scenarios with battery cost reduction assumptions that exceed $50 \%$, BEVs become by far the most important passenger transportation mode. Cost decreases this extensive, however, suggest major technology breakthrough for BEVs.

Battery cost reductions of $60 \%$ with respect to our reference assumptions correspond to bottom battery costs of $130 \$ / \mathrm{kWh}$ in 2040 and thereafter (involving a cost decline of 70\% between 2020 and 2040). This value is substantially lower than the $192 \$ /$ kWh assumed for 2050 by McKinsey [28], but much closer to the cost target of $150 \$ / \mathrm{kWh}$ for long-term commercialisation set by

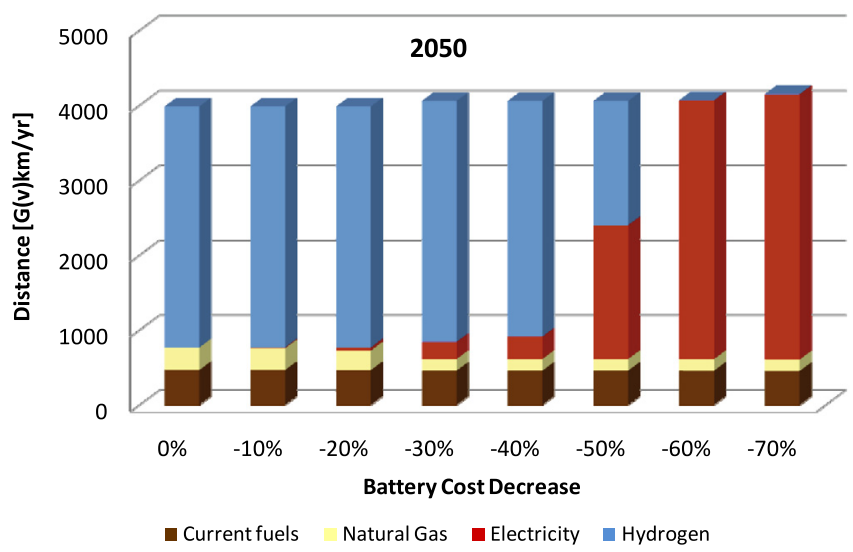

Fig. 7. Distance travelled in 2050 by type of energy carrier (in $G(v) k m / y r$ ) for passenger cars in Europe under stringent climate policy and $100 \$ / \mathrm{bl}$ oil prices with varying assumptions for the cost of batteries (in\% reduction relative to the reference cost assumptions). the US Advanced Battery Consortium [40]. The total cost of a battery pack in a car is determined by both the cost per kWh it can store and the total storage capacity of the battery. The results in Fig. 7 can thus be interpreted in two main ways: as deriving from battery cost reductions per kWh and from the use of smaller battery packs. In our study we assume as a reference, in addition to cost per kWh improvements, a battery capacity of $44 \mathrm{kWh}$ that decreases to $36 \mathrm{kWh}$ for a car with a driving range of $200 \mathrm{~km}$, based on IEA [18] and in line with the size assumptions of the USABC. Besides improvements in the battery cost per $\mathrm{kWh}$, or in the performance of electric cars allowing smaller batteries to yield the same travel distance capability, the adoption of smaller batteries could also reflect the possibility that electric cars will increasingly be used for short distance travelling only. Indeed, McKinsey adopts in its study relatively small battery sizes of $30 \mathrm{kWh}$ and reports that BEVs are most economic for smaller cars and shorter trips. With small battery capacities BEVs would not be able to dominate the passenger car sector completely, since demand would remain for long distance travel and it is unlikely that drivers are willing to recharge or change batteries every $100 \mathrm{~km}$ or so. In such a scenario a mixture between BEVs and FCVs is therefore well imaginable. We do not distinguish between short and long distance car travel in TIAM-ECN and a more in-depth investigation on this is therefore beyond the scope of this study. In light of the travel range problem, also Plug-in hybrid vehicles (PHEV) can play an import role, especially in the first half of the century. PHEV have a smaller battery than BEV, usually around $8 \mathrm{kWh}$, but have an extended driving range due to the additional gasoline or diesel engine. PHEV are included in the TIAM-ECN, but do not appear in the results. One of the main reasons for this may be our conservative assumption regarding the share of PHEV travel fuelled by electricity. We assumed that half of the distance is covered by the battery and the other half of kilometres by the gasoline or diesel engine. If the electric drive is used more, the competiveness of plug-in hybrids may increase. Grahn et al. [10] and Hedenus et al. [13] show that if driving ranges of $200 \mathrm{~km}$ for BEV and $500 \mathrm{~km}$ for PHEV are assumed, PHEV becomes more cost-effective than BEV. With lower battery costs and higher share of electricity driven kilometres PHEV might even become more competitive than FCEV. In the long term, in the presence of an ambitious climate constraint, all diesel/gasoline fuelled cars need to be phased out, however, and the competitive edge of the PHEV over the FCEV would therefore be only temporary.

The $40 \%, 50 \%$ and $60 \%$ battery cost reduction scenarios differ starkly. Fig. 8 depicts for these three cases the time dynamics of how this transformation of the passenger car market may take place. As can be seen, FCVs play no role throughout the century in the $60 \%$ battery cost reduction case, but for the other two scenarios they start contributing by around 2040 and in a matter of two decades dominate the sector. If battery costs reduce by only $40 \%$ with respect to the reference assumptions, FCVs become even by far the most important powertrain option for passenger cars for most of the second half of the century in addition to some modest role for natural gas cars. In the $40 \%$ battery cost reduction case, 2050 is essentially the only year in which BEVs shortly obtain some modest relevance. In the $50 \%$ battery cost reduction scenario, BEVs are introduced in 2050 and continue to play a role of importance until 2100. It proves that their share varies between values of $10 \%$ and $30 \%$ until the end of the century. For the $60 \%$ battery cost decrease path, the market share of BEVs grows rapidly from about 2040 onwards, and BEVs quickly become essentially the only mode of transportation until the rest of the century. We find that the development of ICE vehicles is roughly the same in all three scenarios. The use of ICE cars running on current fuels increases for another two decades, but declines rapidly after 2030 before entirely disappearing during the second half of the century. ICE cars 

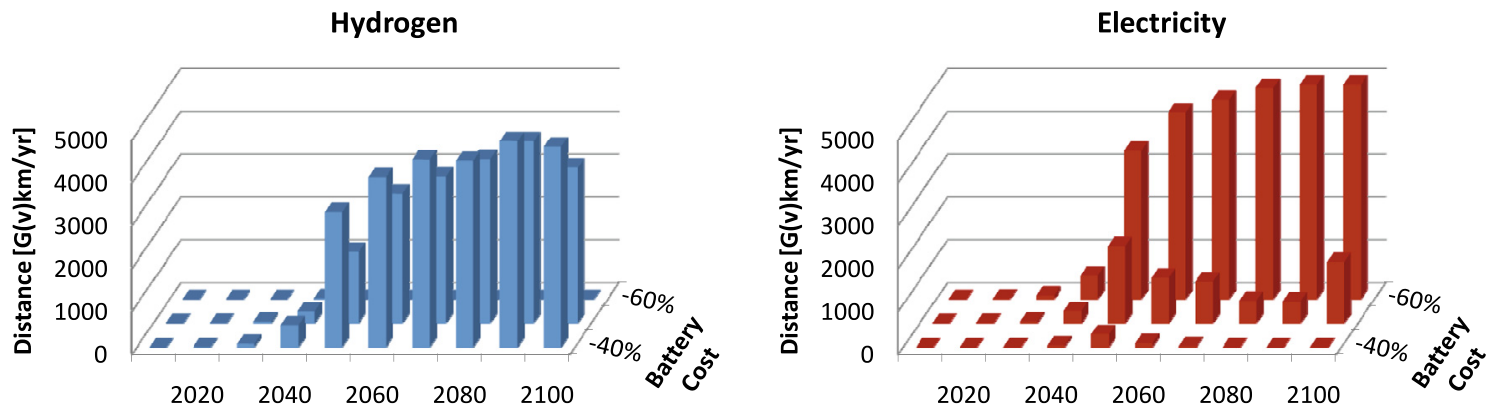

Current fuels

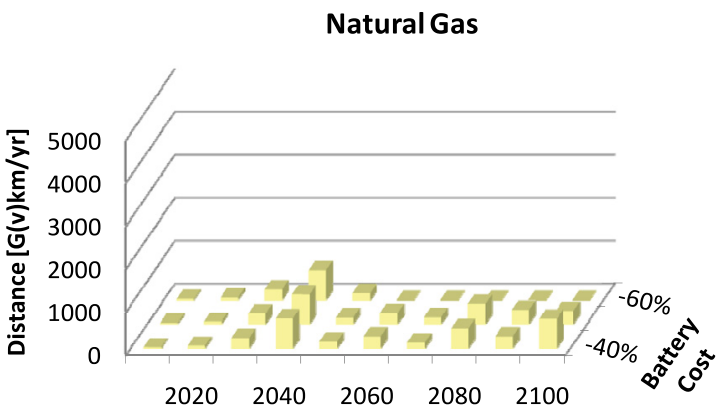

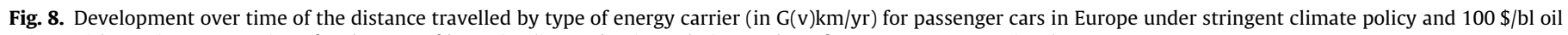
prices with varying assumptions for the cost of batteries (in\% reduction relative to the reference cost assumptions).

running on natural gas undergo more or less the same fate, but peak slightly later, in 2040 and retain a niche market role if the battery cost decrease stays below $60 \%$.

A massive introduction of BEVs requires additional power generation. Fig. 9 shows two graphs with the electricity production mix for, respectively, the scenario with reference battery cost reductions and the one with battery costs $60 \%$ reduced with respect to the reference costs. We observe in Fig. 9(a) a decrease in electricity production for 2020 and 2030 as a result of efficiency improvements and demand reduction stimulated by high energy prices. These decades also yield a transition towards low-carbon and carbon-free generation of electricity from renewable energy sources. After 2030 electricity production increases rapidly, but more or less stabilizes during the second half of the century around a level of approximately $6000 \mathrm{TWh} / \mathrm{yr}$. The additional production derives mostly from an increase in the use of renewable energy sources (in particular solar and wind energy), but important herein is also the expansion of gas power plants equipped with CCS. From 2050 gas power plants with CCS are operated on a large scale and produce about $20 \%$ of total electricity. The contribution of nuclear energy to electricity generation remains approximately constant in absolute terms, in line with recent estimates for the medium term on the basis of mixed reactions from different countries to the accident in Fukushima in March 2011 [42]. Our results show that in the $60 \%$ battery cost reduction scenario, in which BEVs become the dominant passenger cars after 2050, overall electricity production is about $15 \%$ higher during the second half of the century than in the central stringent climate control scenario with reference battery cost assumptions. The additional electricity is mostly produced by plants combusting natural gas, but complemented with CCS technology, while the rest of the production mix remains essentially unchanged.

We also investigate the achievability and robustness of our results in terms of varying assumptions regarding the costs of FCVs. From a learning curve perspective, our fuel cell cost reduction assumptions should match with the deployment of FCVs in our scenario runs and the associated accumulation of experience. Between 2020 and 2040 we assume fuel cell costs to decrease by more than a factor of three, down from 180 to $50 \$ / \mathrm{kW}$, while (a)

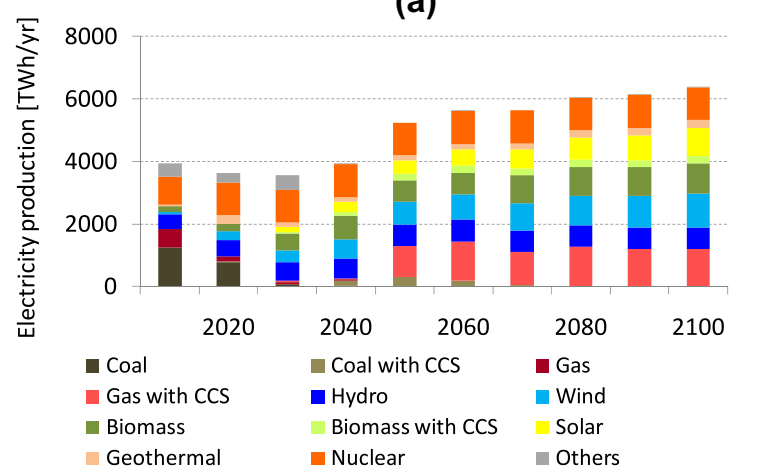

(b)

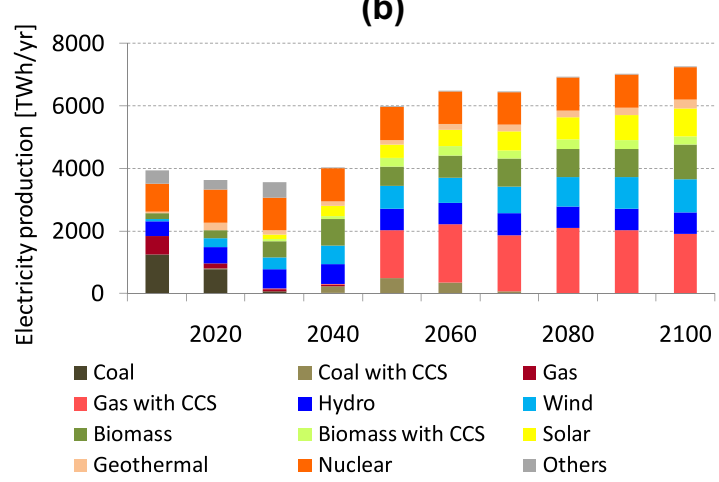

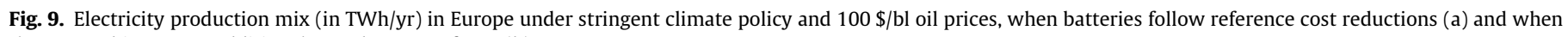
they are subject to an additional cost decrease of $60 \%$ (b). 
the production in our scenario runs grows by an order of magnitude. It proves that these figures are compatible with what so far has been suggested from learning curve analysis for fuel cells. Schoots et al. [36] demonstrate that a learning rate of about $20 \%$ applies to fuel cells, close to the mean empirical value observed across a large range of energy technologies. They find that a $20 \%$ learning rate applies in particular to those fuel cell types that are likely to be installed in FCVs, such as PEMFCs. Ferioli et al. [8] point out that learning rates typically slow down over time and that lower bounds exist to learning - e.g., as a result of basic material input requirements - below which cost reductions cannot fall. It is thus plausible that in 2020 the fuel cell learning rate amounts to $20 \%$, and that this initial learning rate subsequently gradually drops (e.g., by $1 \% / y r$ ) such that by 2040 no further cost reductions take place and technology improvements have mostly been exploited. In TIAM-ECN we assume a 0\% learning rate for fuel cells in 2040. It can easily be shown that this declining learning rate profile, under the expansion of fuel cell capacity that we calculate with TIAMECN, matches with our supposed drop in fuel cell costs.

If, on the other hand, learning for fuel cells is not as steep as we supposed, their ultimate costs will not be as low as we assumed for our central scenario runs. We thus revisit Fig. 7 under the alternative assumption that fuel cells in 2040 cost $100 \$ / \mathrm{kW}$, instead of our central value of $50 \$ / \mathrm{kW}$. Fig. 10 shows that the break-even cost of batteries at which BEVs are broadly introduced rather than FCVs is significantly lowered. At a $20 \%$ cost reduction for batteries we see that in 2050 hydrogen is essentially phased out from passenger cars at the expense of BEVs. The use of BEVs kicks in already at battery cost reductions of $10 \%$. We also see that in 2050 the use of natural gas is substantially more prominent than in our base case.

\section{Further sensitivity tests}

To further examine the robustness of the above results under changes in our key assumptions, we have undertaken additional sensitivity tests for a series of TIAM-ECN's input parameters. We alter not only the intensity of the main driver behind a transition to a low-carbon transport sector - climate change mitigation action - but also vary a range of resource-related and techno-economic factors that either directly or indirectly influence the penetration of new vehicle types.

\section{Additional mitigation efforts}

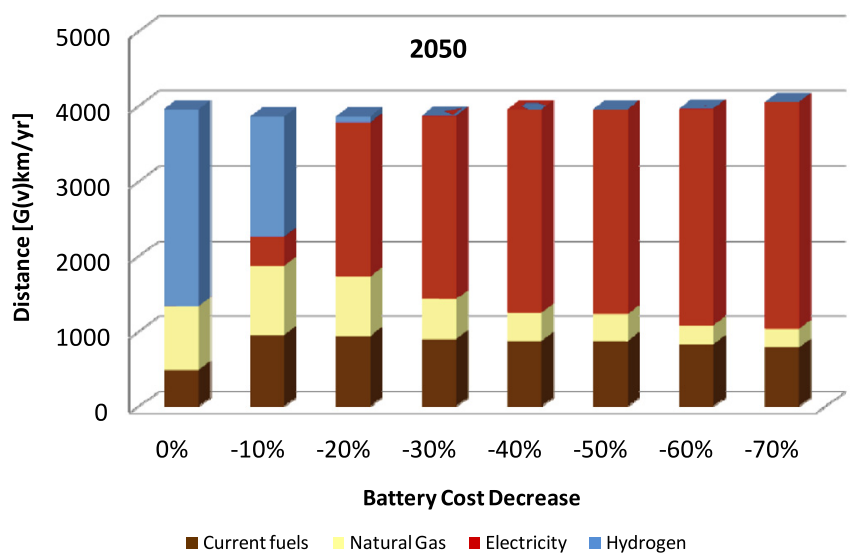

Fig. 10. Distance travelled in 2050 by type of energy carrier (in $G(v) k m / y r$ ) for passenger cars in Europe under stringent climate policy and $100 \$ / \mathrm{bl}$ oil prices with varying assumptions for the cost of batteries (in\% reduction relative to the reference costs assumptions) and moderate fuel cell cost reductions.
By mid-century it may prove that $\mathrm{CO}_{2}$ emission cuts in Europe need to be deeper than the $80 \%$ reduction currently on the political agenda. Suppose that in 2050 it is decided to further strengthen European ambitions in this respect, in comparison to our central stringent climate control case, to a reduction in emissions of $90 \%$ by 2080 and that the absolute emission level reached then needs to be complied with for the remainder of the century. If we apply such a tightened climate mitigation plan, we observe two main changes (see scenario SA1 in relation to the central stringent climate control case (base) in Fig. 11): (1) from around 2060 there is no room anymore for natural gas in the transport sector, and (2) there is great opportunity for BEVs to develop and diffuse from around 2080 onwards (for which no more battery cost reductions are required than those in the reference assumptions). The reason for (1) is that even natural gas is too carbon-intensive under this stringent emission reduction regime. The explanation for (2) is that SMR remains the main technology for hydrogen production: since associated CCS activity possesses an imperfect capture rate (of $90 \%), \mathrm{CO}_{2}$ emissions remain, which are too high under the required extra climate mitigation efforts.

\section{Limited CCS potential}

Whereas most of the energy systems literature depicts CCS as a favourable climate mitigation option with great deployment potential [22], this technology has recently suffered from several political setbacks and may in the future remain constrained by a number of obstacles (as demonstrated by the present slow-down of CCS activity in Europe). Suppose CCS proves ultimately unable to fulfill the promises it currently is believed capable of delivering. Reasons could be of a purely technical or scientific nature, for example if due to physical leakage from geological formations the storage of $\mathrm{CO}_{2}$ does not prove as safe and reliable as it today is thought to be. They could also be non-technical, e.g., if a sceptical public opinion permits the realization of much fewer $\mathrm{CO}_{2}$ storage fields than we assume at present. Scenario SA2 in Fig. 11 shows that if CCS is not available for the production of electricity and hydrogen, biofuels and biogas, the deployment of FCVs around 2050 becomes less dominant than in our central stringent climate control scenario. BEVs make up for the difference, and after 2070 rapidly grow to become the leading passenger car technology in 2100. The phase-out of hydrogen can be explained, first of all, by the unavailability of SMR in a climate-constrained world due to the absence of CCS. The other determinant factor is the competition for, and limited availability of, biomass. Given the unavailability of CCS for SMR and the high costs of electrolysis, hydrogen must be produced from biomass. With steadily increasing global energy demands, however, the consumption of biomass increases to such a level by the end of the century that it becomes more effective to use biomass for generating electricity for BEVs than for producing hydrogen for FCVs (that have a lower efficiency than BEVs).

\section{Limited oil and gas reserves}

As we saw in Fig. 4, even with oil prices that are consistently $150 \$ /$ bl for the rest of the century, our model runs suggest little change in the nature of the passenger car sector with respect to the $100 \$ / b l$ case - in other words, oil, diesel and subsequently natural gas remain the predominant fuels for transportation. We see the same if oil prices are consistently as high as $200 \$ / b l$, so we abstain from further sensitivity tests in this respect. How would this outcome change if fossil fuel reserves are significantly less optimistic, for example as a result of the discarding of oil production from tar sands, and of natural gas from shale formations, e.g., on the basis of environmental concerns? For the results shown under scenario SA3 in Fig. 11 we assume that global oil reserves are only half of what we consider in the central scenarios, while the import of natural gas is reduced by a factor of five and domestically pro- 

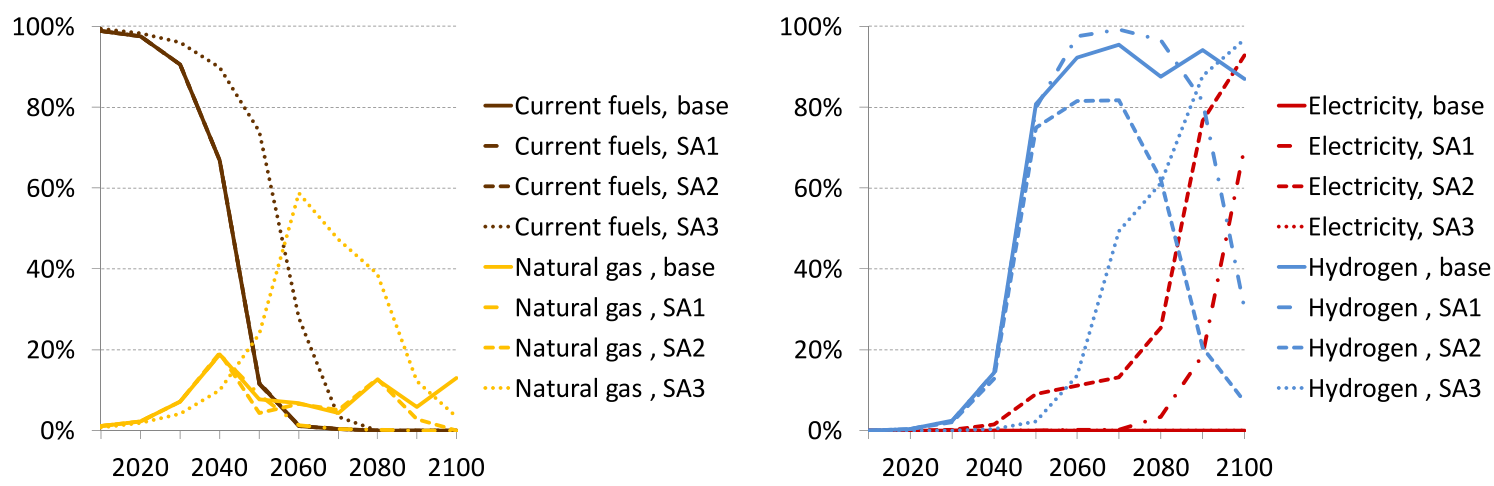

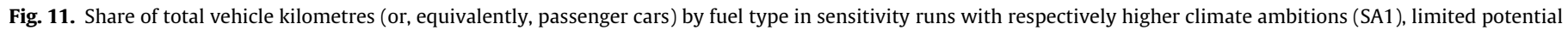
of CCS (SA2) and lower reserves for oil and gas supply and import (SA3).

duced gas (i.e., in East plus West Europe) by a factor of ten. In contrast to scenarios SA1 and SA2, this scenario involves no climate change policy whatsoever. We find that oil use in practically all sectors shifts towards transportation, where it remains the principal fuel during the first half of the century. It is phased out nearly two decades later than in the base case, given the absence of a climate constraint as well as the oil made available used previously in e.g., industry. Natural gas replaces much of oil consumption for several decades around 2060. Given that the use of natural gas is so substantially hampered by production and import limits, however, hydrogen (generated from notably biomass and coal gasification) takes over as energy carrier in the transport sector soon afterwards, occupying the largest share from around 2070 onwards in order to fulfill nearly all transportation requirements by 2100 .

\section{Technology diffusion rates}

One of our most striking results is the massive change of the transport sector around the middle of the century towards hydrogen as main energy carrier: see especially the period 2040-2050 in Fig. 5 , in which growth rates of some $20 \% / \mathrm{yr}$ on average are reached. For other energy technologies the diffusion rates required to reach similar technological growth are not uncommon. For wind power, for instance, an even higher growth rate has been observed, amounting to consistently about $30 \% / \mathrm{yr}$ for the past two decades. The replacement of land lines by mobile phones, involving the construction of required infrastructure of receivers and transmitters, constitutes another interesting case in point, with a diffusion rate of at least the same order of magnitude. Another reason that the large observed expansion of hydrogen use in the transport sector may be realistic is that the FCV technology diffusion phase is preceded by a two-decade maturation period from 2020 to 2040 (that involves an expansion of FCV usage of approximately tenfold during two decades), during which infrastructural and industrial facilities can be built.

Yet multiple hurdles can inhibit a deployment of FCVs as rapid as depicted in Fig. 5, such as the infeasibility of the timely buildup of a hydrogen (pipeline) distribution and fuelling stations network. Also the automobile industry needs to transform profoundly and must be capable of mobilizing the required capital for construction of the corresponding manufacturing capacity. Suppose thus that for the case of FCVs the above high growth rates cannot be realized. Scenario SA4 in Fig. 12 depicts our results if we decrease the maximum allowed annual FCV diffusion rate from 20 to $10 \% / y r$. We see that this yields a major limitation in the diffusion of FCVs. Only by the end of the century the induced delay in the spread of FCVs is almost caught up to reach a market share of around $80 \%$ in 2100 . To provide passenger car services and to reach stringent emission reductions around the middle of the century ICEs using natural gas and BEVs are needed on a large scale for several decades to bridge the gap left by the absence of FCVs. With the diffusion of FCVs in the second half of the century the share of natural gas fuelled cars is substantially reduced and that of BEVs phased out, the former given the global climate constraint and the latter following the relative economic unattractiveness of the electric car.

\section{Technology lifetime}

Another factor influencing the diffusion of new alternative vehicles is their lifetime. One would expect that an increase of the lifetime of cars, assumed in our case the same across different types for ease of exposition, is most beneficent for the more expensive types like FCVs and BEVs. Scenario SA5 in Fig. 12 shows how our central modeling results change under a lifetime increase of passenger cars, from the central value of 12 years up to 15 years. Indeed, we see that the share of FCVs during the second half of the century increases, while the share of ICEs using natural gas is relegated.

\section{Technology discount rates}

Also the discount rate is an important factor determining the diffusion of any technology, since it determines how much relative value one attaches to upfront investment costs as part of the overall costs including those cost components that occur later in the technology's lifetime. A high discount rate discredits technologies with high investment costs. For our central parameter values we assume that technology-specific discount rates are equal to the overall economic planning discount rate $(5 \%)$. If, however, we assume a higher technological discount rate (or hurdle rate) of $15 \%$ for the residential, commercial and private transport sectors, and $10 \%$ for the industrial, power and non-private transport sectors, then BEVs and FCVs clearly have more difficulty in diffusing the vehicle market. This is shown in scenario SA6 of Fig. 12, as a result of which natural gas based ICEs profit. Similarly, increasing the discount rate for individual vehicle types has similar effects for the passenger car under consideration.

\section{Discussion and conclusion}

While for the time being hydrogen as principal fuel in the transport sector seems to have lost much of the attraction it enjoyed a decade ago, electricity appears today the favorite option as the energy carrier for feeding future transportation modes. What arguments can quantitative cost analysis and integrated energy systems modeling contribute to the discussion regarding what type of powertrain technology may or should emerge and broadly diffuse in the long term? This article has attempted to answer this 

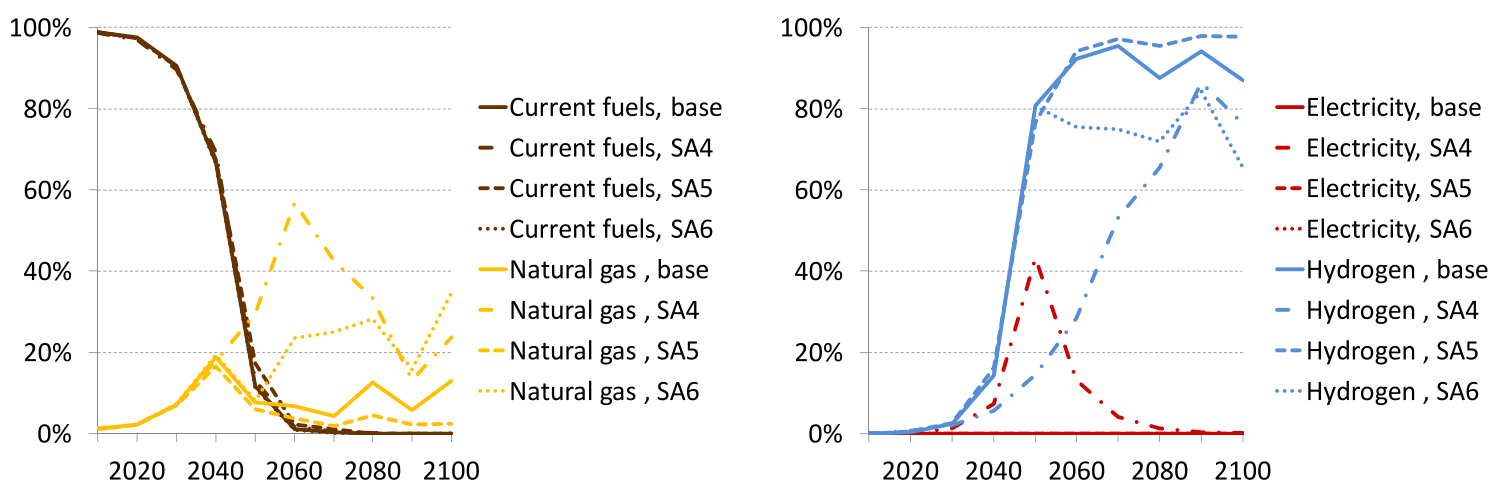

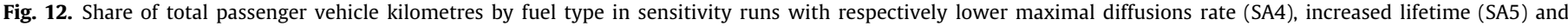
technological specific hurdle rates (SA6).

question through both a concise stylized assessment and a detailed modeling exercise. The latter study, performed with the TIAM-ECN model, suggests that if oil prices remain as high as $100-150 \$ / \mathrm{bl}$ during the remainder of the century and no environmental externalities are internalized, the passenger car sector may continue to rely predominantly on fossil fuels (initially mostly oil and diesel, followed by mainly natural gas, in both cases with secondary roles fulfilled by biofuels) if sufficient reserves of fossil fuels are available at these prices. If ambitious carbon mitigation policies are implemented, however, a massive restructuring of the transport sector away from fossil fuels is likely to take place, which in several decades could transform it so as to broadly rely on hydrogen as main fuel, according to our model runs. We find that if if battery costs are reduced by at least $60 \%$ with regard to our reference cost decrease assumptions, the transportation sector could primarily use electricity as energy carrier from around 2050.

We have undertaken an extensive sensitivity analysis with respect to a large series of input parameters for TIAM-ECN. While sizeable changes in our end results could be observed for modifications in the values of some of them, grosso modo we found no drastic shift in our main conclusion: hydrogen could become an important fuel for the passenger car transport sector during the second half of the century if climate control targets are ambitious or if oil and gas reserves prove to be limited (but not if only their prices are high, even if they are consistently twice as high as their values today). Only in three cases we see electricity play a large to dominant role: (1) when battery costs reduce by $60 \%$ or more with respect to our reference cost reduction assumptions, (2) when fuel cell costs do not fall as rapidly as currently expected on the basis of learning curves (while some additional battery cost reductions still materialize), or (3) when the climate control target is even more ambitious than what we assume in our reference case. We also varied our assumptions with regards to e.g., the maximum allowed diffusion rate of fuel cell vehicles, the lifetime of cars and the discounting values stipulated at various levels of our optimization program. These variations seem not to disqualify hydrogen as important transportation fuel for the second half on the century.

Our detailed modeling efforts with TIAM-ECN assessing the questions how the future passenger car powertrain will look like from an economic planning perspective, confirm our earlier study as well as the more stylistic findings in the first part of our present analysis, in which we showed that natural gas may generally be a very cost-competitive energy carrier for fuelling cars, and that carbon taxation and cost reductions for BEVs and FCVs - depending on the magnitude of these respective stimuli - can at least in principle on the basis of economic arguments make either or both of these car types the ultimate winners [41]. How do our results compare with those reported in the literature on this subject matter? Stud- ies as for example carried out by Grahn [10,11], Gül [12], Akashi and Hanaoka [1], come to the same conclusions. In [2] hydrogen and electricity cars reach almost equal market shares in 2050, but by the end of the century the picture is more diffuse and either electric or hydrogen fuel cell cars are dominating depending on the availability of biomass and CCS or a combination of the two. However, we observe that today many studies appear that justify or argue for a broad diffusion of electric battery-based cars in the short to medium term, especially when short to medium travel distances are considered, rather than hydrogen-based fuel cell cars. Our present study thus deviates from a substantial share of the current literature on this topic.

Among the main reasons for these differences is that our analysis (1) employs a techno-economic perspective only, and (2) inspects the question from an overall energy systems point of view. Many studies (but not all) do not adopt an aggregated energy systems approach, but instead use models that focus on the transport sector only and usually possess more transport-related detail than models covering the full energy system do. Other studies investigating the deployment potential of future car technologies often include arguments other than overall costs, such as infrastructure opportunities or obstacles and specific consumer preferences or habits. Models dedicated to the transport sector often not only allow for the inclusion of more technological detail than we account for, but increasingly also account for behavioral features that may be determinant in this domain. This may be among the explanations for why we obtain conclusions that differ from other works in this field, in addition to the fact that those studies perhaps use more optimistic battery cost reduction assumptions or follow more explicitly the alternating electricity/battery versus hydrogen/fuel cell hype cycle [4]. What the vast majority of analyses dedicated to this topic seem to agree on though, is that transforming transportation will be a major undertaking, in whatever direction this change will ultimately go.

We recognize that our analysis of some important aspects concerning the evolution of the transport sector in Europe is far from exhaustive. As explained, we paid little attention to biofuels used for transportation, since we assume that in the long run their role in Europe may be limited (even while TIAM-ECN simulates biofuels explicitly and includes them in its model outcomes - although in our case mainly for non-passenger car transportation only). This is not to say, however, that in Europe there is no room for biofuel use in transportation, especially for the short and medium term, or that in other countries or regions biofuels may not become predominant in the short or long term: the long history of ethanol use in the Brazilian transportation sector is a good example in case [34]. Also, we have abstracted from the possibility that different car types may in the future be used for different travel distances, and that different niche markets can develop for alternative car 
types. For example, it is not unimaginable that we will ultimately not have just electric or hydrogen cars, but that these two types will co-exist, for instance electric cars for short distances in cities and hydrogen cars for longer travels across countries or continents $[21,28]$. In this paper we also did not extensively consider modal shifts, however much they are part of TIAM-ECN (we did at some length inspect changes in mode of transportation in a previous paper; see [41]. It could well be that eventually more potential for shifts between modes exists (such as between road and rail transportation) than we currently assume. As said, our modelling efforts pertain not only the transport sector, but involve an overall energy systems approach. Analysts using models purely applicable to transportation may well come to different results, as these models can typically much better reflect socio-technical and user-related developments, such as related to shared driving practices, public transportation, systemic changes, and the use of navigation instruments and IT-based traffic control systems, which may ultimately be determinant for the way in which the transportation sector evolves.

\section{Acknowledgements}

The analysis that allowed the publication of this paper was funded by the Netherlands Organisation for Scientific Research (NWO, ACTS Sustainable Hydrogen Programme, contract no. 053.61.024). The work performed under this project also benefited a couple of other studies by the authors, among which for the European Commission funded LIMITS project (FP7/2011-2014, grant agreement no. 282846). Valuable input to this paper and the underlying research from Bert Daniels, Jaap Jansen, Pieter Kroon, Marc Londo, Martine Uyterlinde and Marcel Weeda is greatly acknowledged, as well as from participants of the International Energy Workshop (Cape Town, South Africa, 19-21 June 2012).

\section{References}

[1] Akashi OT, Hanaoka T. Technological feasibility and costs of achieving a 50\% reduction of global GHG emissions by 2050. Sustain Sci 2012:139-56.

[2] Anandarajah G, McDowall W, Ekins P. Decarbonising road transport with hydrogen and electricity: long term global technology learning scenarios. Int J Hydrogen Energy 2013;38:3419-32.

[3] Anderson DL, Patiño-Echeverri D. An evaluation of current and future costs for lithium-ion batteries for use in electrified vehicle powertrains. Nicholas School of the Environment of Duke University; 2009. Master project.

[4] Bakker S. The car industry and the blow-out of the hydrogen hype. Energy Policy 2013;38(11):6540-4

[5] Bruggink JJC, Rösler H. The Economic Feasibility of a Sustainable Hydrogen Economy, In: Proceedings of the 18th world hydrogen conference, WHEC: Essen, Germany; 2010.

[6] Berndes G, Hansson J. Bioenergy expansion in the EU: cost-effective climate change mitigation, employment creation and reduced dependency on imported fuels. Energy Policy 2007;35(12):5965-79.

[7] Capros P, Tasios N, De Vita A, Mantzos L, Paroussos L. Transformations of the energy system in the context of the decarbonisation of the EU economy in the time horizon to 2050. Energy Strat Rev 2012;1(2):85-96.

[8] Ferioli F, Schoots K, van der Zwaan BCC. Use and limitations of learning curves for energy technology policy: a component-learning hypothesis. Energy Policy 2009;37:2525-35.

[9] Gitiaux X, Rausch S, Paltsev S, Reilly JM. Biofuels, climate policy, and the European vehicle fleet. J Trans Econ Policy 2012;46(1):1-23.

[10] Grahn M, Azar C, Williander MI, Anderson JE, Mueller SA, Wallington TJ. Fuel and vehicle technology choices for passenger vehicles in achieving stringent $\mathrm{CO}_{2}$ targets: connections between transportation and other energy sectors. Environ Sci Technol 2009:43:3365-71.

[11] Grahn M, Anderson JE, Wallington TJ, Williander M. The role of ICEVs, HEVs, PHEVs, BEVs and FCVs in achieving stringent $\mathrm{CO}_{2}$ targets: results from global energy systems modeling. W Electric Vehicle J (WEVA) 2009;3 [ISSN 20326653].

[12] Gül T, An energy-economic scenario analysis of alternative fuels for transport, PhD Thesis No. 17888, ETH Zürich, Switzerland, 2008.
[13] Hedenus F, Karlsson S, Azar C, Sprei F. Cost-effective energy carriers for transport - the role of the energy supply system in a carbon-constrained world. Int J Hydrogen Energy 2011;35(10):4638-51.

[14] Hendriks C, Graus W, van Bergen F. "Global carbon dioxide storage potential and costs", Report EEP-02001. The Netherlands: Ecofys and TNO; 2004.

[15] HyWays, 2008, The European Hydrogen Roadmap, European Community, Brussels, downloadable from: www.hyways.de.

[16] IEA. Prospects for hydrogen and fuel cells. Paris: International Energy Agency; 2005.

[17] IEA. Energy technology essentials: fuel cells. Paris: International Energy Agency; 2007.

[18] IEA. Transport, energy and $\mathrm{CO}_{2}$ : moving towards sustainability. Paris: International Energy Agency; 2009.

[19] IEA. World energy outlook 2009. Paris: International Energy Agency; 2009.

[20] IEA. Energy technology perspectives 2010 - scenarios \& strategies to 2050. Paris: International Energy Agency; 2010.

[21] IEA. Energy technology perspectives 2012. Paris: International Energy Agency; 2012.

[22] IPCC. Special report on carbon dioxide capture and storage, Working Group III. Intergovernmental Panel on Climate Change, Cambridge University Press; 2005.

[23] Keppo I, van der Zwaan BCC. The impact of uncertainty in climate targets and $\mathrm{CO}_{2}$ storage availability on long-term emissions abatement. Environ Model Assess 2012;17(1-2):177-91.

[24] Kyle K, Kim SH. Long-term implications of alternative light-duty vehicle technologies for global greenhouse gas emissions and primary energy demands. Energy Policy 2011;39:3012-24.

[25] Lebutsch P, Weeda M. THRIVE: study on roll-out of fuel cell electric vehicles and hydrogen refuelling infrastructure for the Netherlands, ECN-E-11005. Petten, The Netherlands: ECN; 2011.

[26] Loulou R, Labriet M. ETSAP-TIAM: the TIMES integrated assessment model Part I: model structure. CMS 2008;5(1-2):7-40.

[27] Loulou R. ETSAP-TIAM: the TIMES integrated assessment model, Part II: mathematical formulation. CMS 2008;5(1-2):41-66.

[28] McKinsey, 2010, A Portfolio of power-trains for Europe: a fact-based analysis the role of battery electric vehicles, plug-in hybrid electric vehicles and fuel cell electric vehicles.

[29] NRC. Transitions to alternative transportation technologies: a focus on hydrogen. Washington (DC): National Research Council of the National Academies; 2008.

[30] Offer GJ, Howey D, Contestabile M, Clague R, Brandon NP. Comparative analysis of battery electric, hydrogen fuel cell and hybrid vehicles in a future sustainable road transport system. Energy Policy 2010;38(1):24-9.

[31] RES2020, 2009, Monitoring and evaluation of the RES directives implementation in EU27 and policy recommendations for 2020, EU27 Synthesis Report, downloadable from: http://www.cres.gr/res2020/.

[32] Rivera-Tinoco R, Schoots K, van der Zwaan BCC. Learning curves for solid oxide fuel cells. Energy Convers Manage 2012;57:86-96.

[33] Rösler H, Bruggink JJC, Keppo IJ, Design of a European sustainable hydrogen model, Report ECN-E-11-041, ECN, Petten, The Netherlands; 2011.

[34] Sandalow D, Ethanol: lessons from Brazil, In: Ewing TW, Woolsey RJ, A high growth strategy for ethanol, Appendix F, Aspen Institute; 2006

[35] Schäfer A, Heywood JB, Jacoby HD, Waitz IA. Transportation in a climateconstrained world. MIT Press; 2009.

[36] Schoots K, Kramer GJ, van der Zwaan BCC. Technology learning for fuel cells: an assessment of past and potential cost reductions. Energy Policy 2010;38:2887-97.

[37] Syri S, Lehtilä A, Ekholm T, Savolainen I, Holttinen H, Peltola E. Global energy and emissions scenarios for effective climate change mitigation deterministic and stochastic scenarios with the TIAM model. Int J Greenhouse Gas Control 2008;2(2):274-85.

[38] Takeshita T, Yamaji K. Important roles of Fischer-Tropsch synfuels in the global energy future. Energy Policy 2008;36:2773-84.

[39] Turton H, Barreto L. Impact assessment of energy-related policy instruments on climate change and security of energy supply. Int J Global Energy Issues 2007;27(1):15-41.

[40] USABC, "Goals for Advanced EV Batteries", downloadable from: www.uscar.org/guest/teams/12/U-S-Advanced-Battery-Consortium [last consulted August 2012].

[41] van der Zwaan BCC, Keppo IJ, Johnsson F. When and how to decarbonize the transport sector? Energy Policy 2012;61(2013):562-73.

[42] van der Zwaan BCC. The role of nuclear power in mitigating emissions from electricity generation. Energy Strat Rev 2012;1(4):296-301.

[43] van Ruijven B, van Vuuren DP. Oil and natural gas prices and greenhouse gas emission mitigation. Energy Policy 2009;37:4797-808.

[44] van Vliet OPR, Kruithof T, Turkenburg WC, Faaij A. Techno-economic comparison of series hybrid, plug-in hybrid, fuel cell and regular cars. J Power Sources 2010;195:6570-85.

[45] Yeh S, Lutsey NP, Parker NC. Assessment of technologies to meet a low carbon fuel standard. Environ Sci Technol 2009;43(18):6907-14. 